\title{
UN ACERCAMIENTO A LA VIDA COTIDIANA EN LOS PRIMEROS AÑOS DEL ISLAM EN EL NORTE DE LA PENÍNSULA IBÉRICA: UNA COCINA DEL SIGLO VIII D.C. EN EL PUEYO (LOS BAÑALES, UNCASTILLO, ZA). II. LA CERÁMICA*
}

\author{
AN APPROACH TO THE DAILY LIFE IN THE EARLY YEARS \\ OF ISLAM IN THE NORTH PART OF THE IBERIAN PENINSULA: \\ AN EIGHTH CENTURY KITCHEN IN EL PUEYO \\ (LOS BAÑALES, UNCASTILLO, ZA). II. POTTERY
}

Diana Vega Almazán, Ángel A. Jordán, Javier Muruzábal Cal y Vega Orozco legaza Universidad de Cantabria-Archivo Epigráfico de Hispania-Proyecto Arqueológico de Cabeza Ladrero dvalmazan@gmail.com ORCID: 0000-0002-6474-6819 ajorlor@yahoo.es

ORCID: 0000-0001-7557-981X jmuruzabalcal@gmail.com

ORCID: 0000-0003-3049-2472 vegaalfalyra@gmail.com

ORCID: 0000-0001-5572-2770

DOI: $10.1387 /$ veleia.18081

Resumen: El objetivo del presente trabajo es dar a conocer los resultados de la excavación de una cocina datada en la segunda mitad del siglo viıI d.C. en El Pueyo (Los Bañales, Uncastillo). La calidad y cantidad del material recuperado permiten realizar un acercamiento de primera mano a la vida cotidiana de la sociedad en un momento muy poco conocido. Continuando el trabajo publicado en el anterior volumen de Veleia, en esta ocasión se analizará la cerámica.

Palabras clave: El Pueyo, Los Bańales, siglo viıI, Islam, Cocina, Cerámica.

Abstract: The aim of this paper is to present the results of the excavation of a kitchen dated in the 8th century AD in El Pueyo (Los Bañales, Uncastillo). The quality and quantity of the recovered material allow us to draw important conclusions about the everyday life

* Continuación de la primera parte, publicada en el número anterior de la revista Veleia. 
of a society at a poorly known time. The analysis of this interesting space, which began in a paper published in the previous Veleia issue, is closed in this paper devoted to the pottery.

Keywords: El Pueyo, Los Bañales vin Century AD, Felus, Islam, Kitchen, Pottery.

Recibido: 03-02-2015

Informado: 16-03-2015

Definitivo: 03-03-2017

\section{INTRODUCCIÓN}

Se continúa en estas páginas el estudio de los materiales encontrados durante la excavación en 2012 de una cocina (A4) encontrada en El Pueyo (Los Bañales, Uncastillo), cuya destrucción fue debida a un incendio, posiblemente en la segunda mitad del siglo viII d.C. (Jordán et al. 2016, 145). En relación con ello, el volumen y calidad de material encontrado fue tan grande que aconsejó su publicación en dos artículos distintos. En el primero, que se puede encontrar en el anterior número de esta revista (Jordán et al. 2016), se abordaron los aspectos arqueológicos de la excavación así como el estudio de los objetos metálicos y restos óseos ${ }^{1}$. En éste se centrará la atención en los restos cerámicos.

Como se vio en la primera parte de este trabajo, el espacio excavado, de $22 \mathrm{~m}^{2}$, es el resultado de la ocupación continua de la vivienda, que favoreció sucesivas reformas (Jordán et al. 2016, 142145). Tal y como ha llegado, la habitación resultante se muestra como un espacio ciego al exterior, por lo cual quizá se emplazó un gran hogar cerca de la entrada, cuya apertura de humos permitía aprovechar mejor la luz diurna. Además, su carácter recogido tal vez la convirtió en el centro neurálgico de la casa, lugar donde se cocinaba y trabajaba, como muestran los restos de cornamenta de ciervo identificados (Jordán et al. 2016, 156).

En este contexto espacial, la distribución de clavos encontrados durante la excavación (Jordán et al. 2016, 147-148) muestra una disposición del mobiliario adosado a las paredes y, por lo tanto, dejando el espacio central de la habitación y el inmediatamente al lado del fuego vacíos o bien, más probablemente, ocupado por otro tipo de enseres (mesas, sillas) de los que no se han conservado testimonios. Se desconocen los tipos de muebles que ocuparían la habitación, aunque la cantidad de clavos invita a pensar que, quizá, en la pared Oeste y posiblemente en el ángulo NE habría estanterías mientras que en el ángulo SE bien pudo existir un mueble más complejo, decorado con apliques de bronce. Por el contrario, la pared Sur tal vez permanecería vacía o, al menos, no se han encontrado restos de ningún tipo de mobiliario.

Es en este entorno claramente doméstico donde se han podido localizar 488 fragmentos cerámicos, de entre los cuales se han podido identificar veinticinco recipientes, que se analizarán a continuación.

\section{LA PRODUCCIÓN CERÁMICA: ASPECTOS GENERALES}

El período comprendido entre los siglos vir y viII d.C. estuvo afectado por transformaciones de largo alcance que influyeron en los ámbitos de producción cerámica y en las relaciones comerciales.

1 En relación con la anterior publicación, quisiéramos disculparnos por un error que cometimos en la figura 12. Como se puede apreciar, por equivocación incluimos la imagen de un tarsometatarso de una galliná- cea en vez del fragmento de maxilar de Canis L. Familiaris que se pretendía. También nos gustaría aprovechar la ocasión para agradecer a Marcos García García y Marta Moreno-García su llamada de atención al respecto. 
El vínculo que existía entre el campo y la ciudad sufrió importantes cambios que originaron nuevos modelos de asentamiento. Además, el sistema económico imperante en las regiones del Mediterráneo occidental desde época romana entró en crisis entre los siglos v y viI d.C. lo que produjo una desarticulación de las redes comerciales que conllevó un descenso en la importación de cerámica común africana paralelo a una menor presencia de las vajillas de mesa.

Centrando la atención en la Península Ibérica, la cerámica modelada a mano y a torno lento tuvo una gran importancia a partir del siglo vi d.C. y, especialmente, en los siglos vir y viII d.C. Este modelo productivo tenía un carácter doméstico y se realizaba en talleres particulares con tecnología elemental, de tal forma que los excedentes cerámicos se comercializaban dentro del área de influencia del propio poblado, posiblemente como complemento a una economía de subsistencia que caracterizaba a la sociedad agraria de esta época. Formalmente se aprecia una preferencia por las vasijas de perfil cerrado con cuello corto y cuerpo de tendencia globular. La pared suele ser gruesa y de arcilla poco depurada y la mayoría parece derivar de formas tardorromanas. Con respecto a su cocción, en el siglo viI d.C. predominan las cocciones reductoras pero a mediados y finales del siglo viII d.C. comienzan a aparecer pastas de colores claros que van desde el marrón hasta tonalidades rojizas y anaranjadas. Este hecho podría indicar la existencia de unos sistemas de cocción tecnológicamente más avanzados que en el período anterior.

También se ha podido constatar una heterogeneidad morfológica en función de los diferentes núcleos de asentamiento. En relación con ello, puede considerarse que la ausencia de una producción centralizada dio lugar a la búsqueda de soluciones específicas para los hábitos alimenticios de cada zona. La consecuencia de esta diversidad en las manufacturas es la dificultad para realizar un estudio comparativo de las tipologías cerámicas procedentes de diferentes yacimientos peninsulares insertos en el mismo ámbito cultural.

Otro de los problemas que existen a la hora de estudiar las producciones del siglo viII d.C.es la ausencia de un «fósil director». El fin de la importación de vasijas africanas junto a la desaparición de la vajilla fina ha dificultado la correcta asignación cronológica a estos conjuntos atribuyéndoles, en algunos casos, dataciones más tempranas. Sin embargo, en las dos últimas décadas se han realizado numerosos trabajos que han permitido conocer mejor las técnicas utilizadas en la manufactura de la cerámica encuadrada entre los siglos vir y viII d.C., así como su morfología y desarrollo tipológico.

Como se ha dicho con anterioridad, el principal lote de piezas recuperado en la excavación del espacio A4 es cerámico. Los 488 fragmentos recuperados han permitido la identificación de veinticinco recipientes de diferente naturaleza tecnológica, con cierto predominio de ollas y cazuelas, centrándose su estudio en analizar el origen, evolución tipológica y funcionalidad de este lote. Con este fin se ha realizado un análisis comparativo de estas piezas con otras procedentes de los yacimientos peninsulares mejor estudiados hasta el momento e insertos en el mismo ámbito cronológico. También se ha analizado la presencia o ausencia de huellas de uso en cada pieza y su posible relación con los restos óseos encontrados en dicha estancia.

En general, el principal criterio de clasificación aplicado en su estudio está basado en los diferentes sistemas productivos utilizados en la manufactura de las piezas. De esta forma, se aprecia el predominio de las cerámicas comunes de arcilla basta realizadas a mano o mediante el uso de un torno lento, representando el $81 \%$ del total (fig. 1). Por otra parte, también existe, aunque de forma minoritaria pues apenas supone un $19 \%$ del total de piezas localizadas, un pequeño grupo de vasijas elaboradas a torno, con arcillas depuradas y engobes externos de clara tradición romana. 


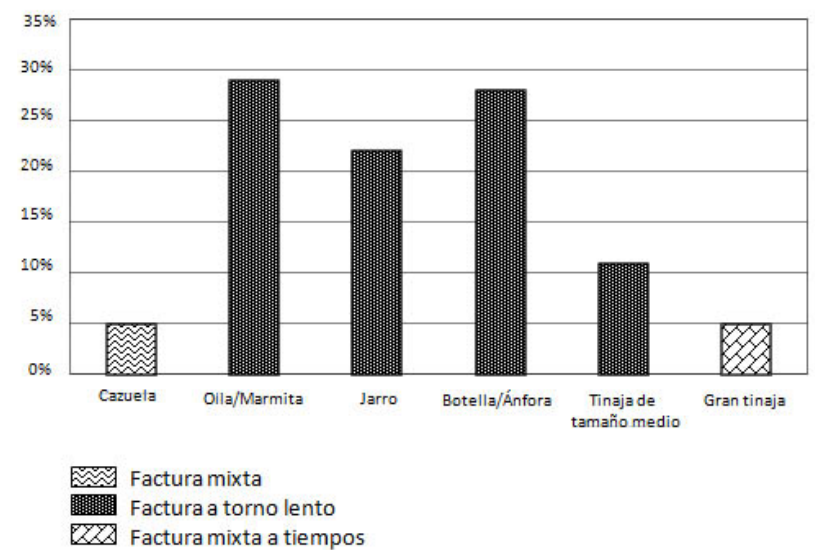

Figura I. Tipología de la cerámica de cocina

\section{Cerámica común}

La cerámica común es un tipo de producción relacionada con ámbitos domésticos, por lo que no asombra su predominio, estando representada por 18 vasijas de diferentes morfologías entre las que imperan las formas cerradas. Son piezas de aspecto muy basto realizadas con arcillas sin decantar y con presencia de desgrasantes de grandes dimensiones entre los que destacan cuarcitas, calcita, chamota y mica. Puesto que el uso de arcillas con abundantes impurezas relacionadas con sistemas productivos de tipo doméstico y una baja temperatura de cocción le confiere a estas piezas unas propiedades térmicas que las hacen muy resistentes al fuego, no sorprende constatar que esta técnica es la que más se usa en el ámbito de las cerámicas culinarias.

En relación con ello, se aprecia una mayor presencia de piezas elaboradas con arcillas en tonos marrones y anaranjados que indican un predominio de procesos de cocción en atmósferas oxidantes «tipo C». A este grupo le sigue en representación un conjunto de vasijas pertenecientes al «tipo A» con pastas de núcleo grisáceo, debido a una cocción reductora, y superficies de tonalidades marrones como consecuencia de una atmósfera final oxidante. También se han identificado piezas con pastas de color gris debido a una cocción reductora «tipo $\mathrm{B}$ « $\mathrm{y}$ un pequeño porcentaje de cerámicas de cocción oxidante y post-cocción reductora «tipo D» (Beltrán 1990, 24) (fig. 2).

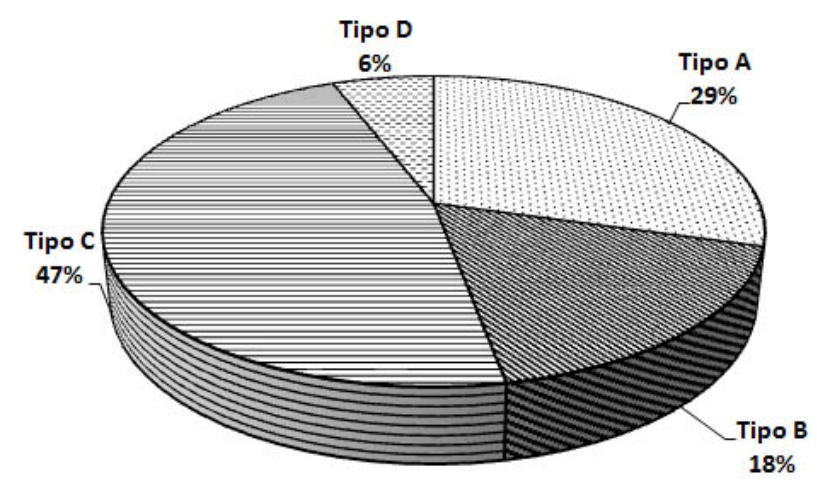

Figura 2. Distribución porcentual del tipo de cocciones identificadas 
En general, el repertorio formal, definido por criterios morfológicos y funcionales, es reducido y está representado por cazuelas de perfil en "S« con bases convexas y boca amplia (fig. 3, n. ${ }^{\circ}$ 1;

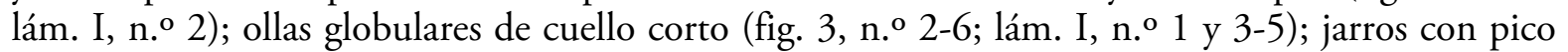
vertedor estrangulado y boca redondeada o con caño vertedor independiente del borde (fig. 5 , n. ${ }^{\circ} 2-4$; lám. II, n. ${ }^{\circ} 2-3$ ); botellas de cuerpo piriforme con asa (fig. 8, n. ${ }^{\circ} 1$; lám. III, n. ${ }^{\circ} 1$ ); jarros de boca amplia y borde exvasado (fig. 5 , n. ${ }^{\circ} 1$; lám. II, n. ${ }^{\circ} 1$ ) y contenedores de almacenaje de tamaño medio y grande (fig. 9 , n. ${ }^{\circ} 1-3$; lám. IV, n. ${ }^{\circ} 1-3$ ), que serán analizados con detenimiento en las siguientes páginas. La superficie externa de las vasijas suele estar alisada por medio de espátulas y en ocasiones se observa evidencias de bruñido. Un alto porcentaje de las piezas presenta decoración (60\%). La técnica empleada con mayor profusión es el estriado en forma de acanaladuras paralelas que cubren el cuerpo y la parte superior del recipiente (fig. 3 , n. ${ }^{\circ} 6$; fig. 3 , n. ${ }^{\circ} 1$ y 3 ; lám. I, n. ${ }^{\circ}$ 5; lám. II, n. ${ }^{\circ} 1$ y 3 ; lám. IV, n. ${ }^{\circ} 3$ ). También se utiliza la incisión de bandas paralelas y entrecruzadas formando una especie de enrejado irregular (fig. 9, n.o 1-2; lám. IV, n. ${ }^{\circ} 1-2$ ).

\subsection{Cazuelalmarmita}

Con esta denominación se identifican a recipientes sin cuello, de boca muy amplia y con un diámetro superior a la altura del vaso. Suelen tener base convexa y a menudo presentan huellas de uso que evidencian su exposición al fuego. Las vasijas con este tipo de fondo son idóneas para la cocción prolongada de guisos con abundante líquido (Roselló Bordoy 1991, 168), para lo cual se colocaban sobre una trébede o, si no eran demasiado grandes, se colgaban mediante cuerdas sobre la hoguera. La excavación de la cocina ha permitido el descubrimiento de un ejemplar (12.36.831) en el ángulo NW de la estancia, con restos óseos de Capra A. Hircus asociados (12.36.437 y 740).

\subsubsection{Cazuela, inv. n. ${ }^{\circ} 12.36 .831$ (fig. 3, n.o 1; lám. I, n.o 2)}

Marmita o cazuela de perfil en «S», borde curvo y exvasado y labio biselado hacia el exterior, base ligeramente abombada y asa vertical de cinta en uno de sus laterales con un rehundimiento en su unión con el cuerpo del recipiente. La pasta es tosca de color marrón con un grosor de $0,89 \mathrm{~cm}$ y desgrasantes de calcita, chamota y vegetales. Muestra cocción «tipo C». La presencia de improntas digitales en la unión de la base con el cuerpo de la pieza evidencia un tipo de modelado mixto: por un lado se elaboró el fondo de forma manual y después se unió al resto de la vasija fabricada previamente mediante un torno lento. El acabado de la pieza se ha realizado por medio de un alisado interno y externo. Dimensiones: altura, $11,5 \mathrm{~cm}$; diámetro de la boca, $19 \mathrm{~cm}$; diámetro del fondo, $21,5 \mathrm{~cm}$.

Conviene resaltar que se han encontrado huellas de uso causadas por la acción del fuego en la totalidad de la pared externa de la pieza, que indican una función culinaria relacionada con la elaboración de alimentos. Sin embargo, aunque se pueda pensar que se trataba de un recipiente apto para la cocción prolongada, existen numerosas perforaciones circulares de $1 \mathrm{~cm}$ de diámetro en la base y en la zona inferior del cuerpo, realizadas con posterioridad a la cocción de la pieza y que se identifican como lañas de reparación. Estos orificios inutilizaron la función inicial de la marmita como utensilio para la elaboración culinaria por lo que pudo tener un segundo uso, bien como recipiente para la preparación previa de los alimentos antes de ser cocinados o bien como escurridor.

En los yacimientos de Fontcalent y de la Alcudia (Alicante) se encontraron marmitas con el mismo tipo de pasta, factura, acabado y cocción, fechadas a finales del siglo vil d.C. y principios del viII d.C. (Gutiérrez 1996, 73-74). También existen paralelos en cerámicas de la clase «TL 2» de los yacimientos de Gózquez, La Indiana y Fuente de la Mora (Madrid) con fondos ligeramente convexos y enmarcados en el mismo ámbito cronológico (Vigil-Escalera 2003, 378 y 380). 


$$
\begin{array}{ll}
2 & 0 \\
1 & 0 \\
0.19
\end{array}
$$



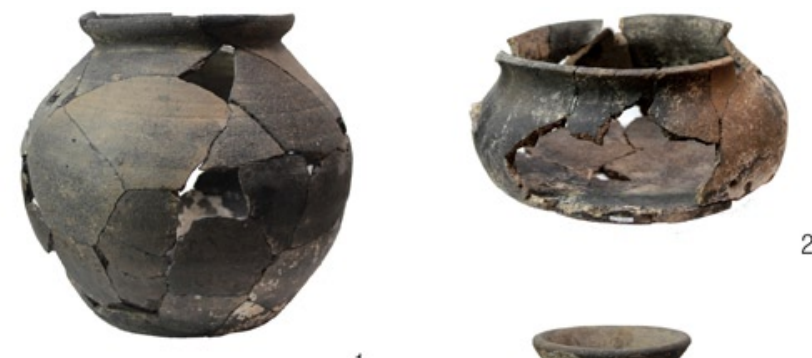

1
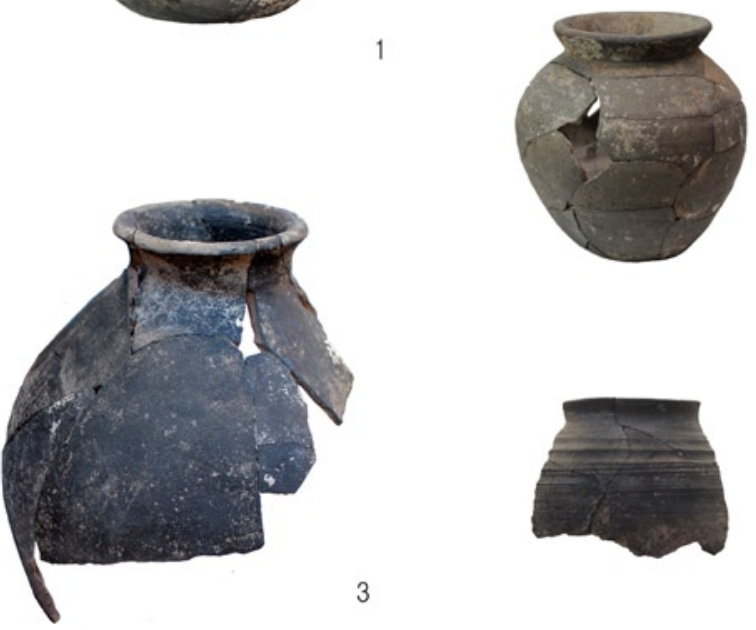

4

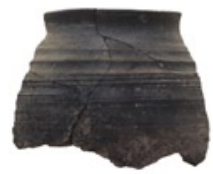

5
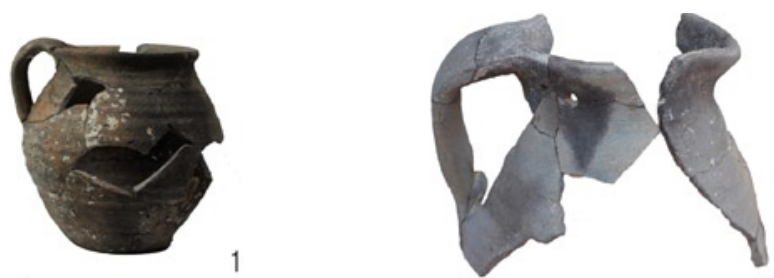

2
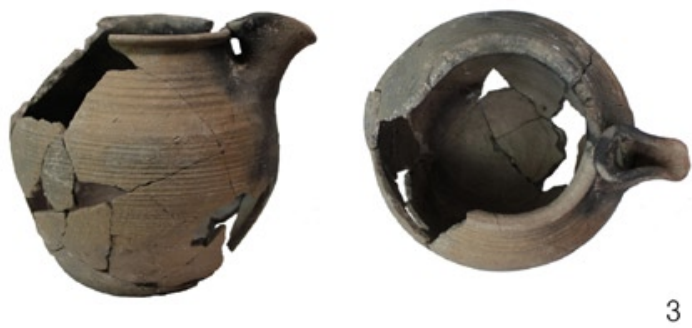

3

LÁMINA II 
170 DIANA VEGA ALMAZÁN, ÁNGEL A. JORDÁN, JAVIER MURUZÁBAL CAL y VEGA OROZCO LEGAZA
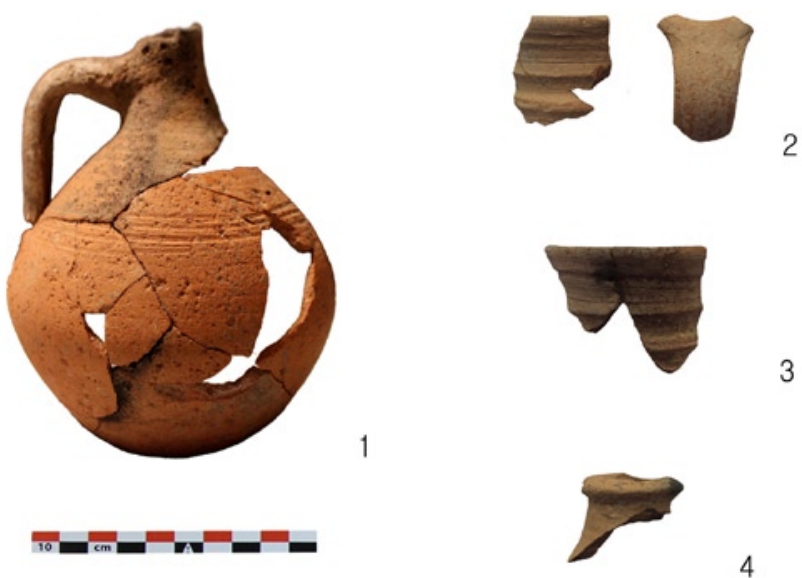

LÁMINA III
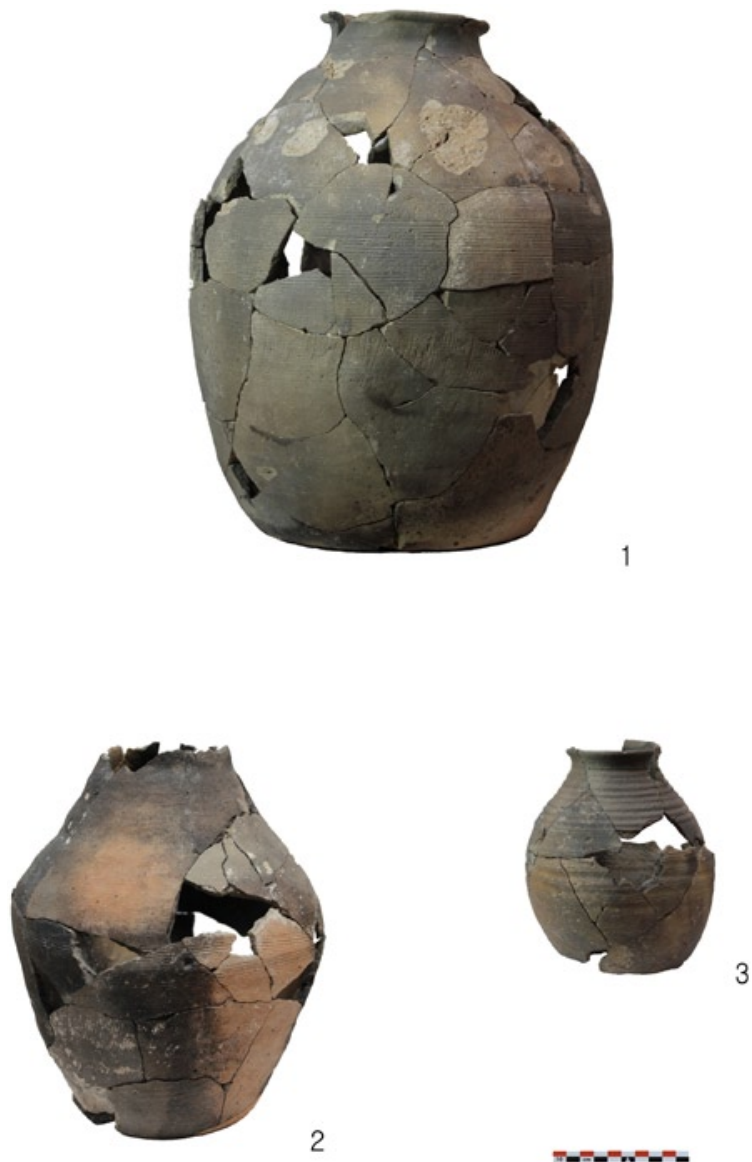

LÁMINA IV 

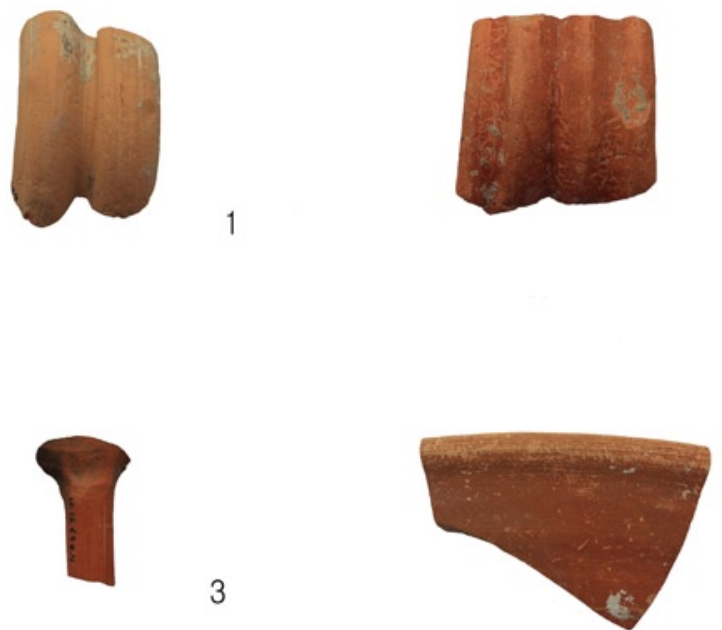

\section{4}

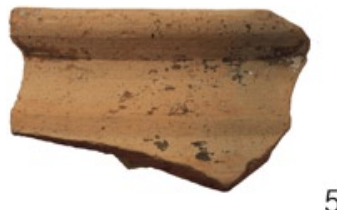

5

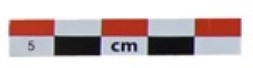

LÁMINA V

\subsection{Ollalmarmita}

Con esta nomenclatura se identifican recipientes altos, de boca amplia y uso culinario. La excavación de la cocina ha permitido el hallazgo de cinco ollas, caracterizadas por la forma globular de su cuerpo, acompañada por un cuello corto y curvo y el borde exvasado. Las bases pueden ser tanto planas como convexas y presentan huellas de uso que evidencian su exposición al fuego. En ocasiones pueden presentar asas aunque no se han documentado suspensiones de este tipo en las vasijas estudiadas.

En general, este tipo de ollas tienen una clara función culinaria, relacionada con la elaboración de alimentos sólidos o líquidos. Esta función es claramente explícita por las huellas de uso causadas por la acción del fuego en la pared externa de la pieza, apreciada en la mayor parte de las ollas; el tipo de cocción de la vasija a baja temperatura como, por ejemplo, 12.36.830; la abundancia de desgrasantes en la arcilla que aporta una resistencia térmica óptima; y la forma convexa de la base. Además, en el caso de la olla 12.36.827 en algunos yacimientos como el de Arcávica se han hallado formas semejantes que contenían nueces y almendras carbonizadas (Álvarez 1989, 112), es decir, alimentos de pequeño tamaño acorde con sus dimensiones. Junto a este uso, claramente culinario, en algunos casos tampoco puede descartarse que algunas de ellas, como 12.36.821, en ocasiones sirvieran para contener o almacenar productos. 
La dispersión de los restos cerámicos en la habitación es desigual: coexisten ejemplares cuyos restos muestran una gran concentración quizá indicativo de una posible ubicación del objeto próxima al lugar donde se encontraron sus fragmentos en un momento previo a la amortización (destrucción) de la habitación (i.e. 12.36.830, cerca del muro Norte, en G2 y F2), con otros cuyos fragmentos adoptan una dispersión en diagonal, en forma de cuña, lo cual quizá podría estar indicando una caída desde cierta altura (i. e. 12.36.821, entre F7 y H1). Por su parte, también los restos de 12.36.827 tienen una dispersión en forma de cuña que parte desde G1 y termina en I3, aunque en este caso, dada la acumulación de material en G1, pudo estar alojada en la pared Oeste. En esta misma pared también pudo estar guardada la olla 12.36.824, cuyos restos aparecen en diagonal entre G1 y F7. Por su parte, la olla 12.36.498 muestra una dispersión entre H1/I1 y F4/H4 (fig. 4).

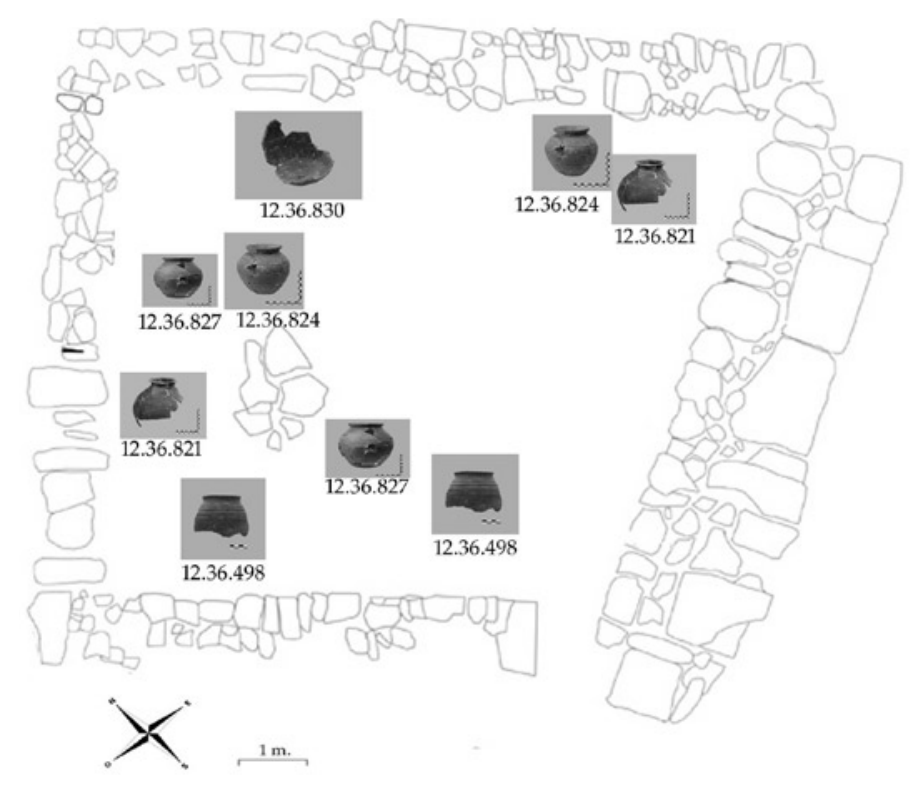

Figura 4. Distribución (aproximada) de los restos recuperados de cazuelas/marmitas en A4

\subsubsection{Olla, inv. n. ${ }^{\circ} 12.36 .821$ (fig. 3, n. ${ }^{\circ} 3$; lám. I, n.o 3)}

Gran olla o marmita de forma globular. Muestra una boca amplia de 12,4 cm de diámetro, borde exvasado, labio engrosado y redondeado y cuello curvo. No conserva la base y no se ha documentado algún tipo de suspensión. La pasta es tosca de color marrón con un grosor de $0,49 \mathrm{~cm}$ y muestra desgrasantes de calcita y chamota. Presenta una cocción "tipo D» y una factura a torno lento con alisado interno y espatulado externo.

Este tipo de ollas enlazan con la tradición visigoda, habiéndose encontrado ejemplares de características similares a ésta en el yacimiento de Vilaclara (Castellfollit del Boix, Barcelona), fechadas a partir del siglo viI d.C., y en el yacimiento de El Zambo (Novelda, Alicante) datados en torno a la segunda mitad del siglo viII d.C. y la primera mitad del siglo IX d.C. (López et al. 2003, 45 y 53; Gutiérrez 1993, 49-50). 
3.2.2. Olla, inv. n.o 12.36 .827 (fig. 3, n.o 5; lám. I, n.o 1)

Olla o marmita de cuerpo hiperboloide con una altura de $21 \mathrm{~cm}$, boca amplia de $14 \mathrm{~cm}$ de diámetro, borde exvasado, labio redondeado y cuello curvo. La base es plana de $18 \mathrm{~cm}$ de diámetro y no se ha observado ningún tipo de suspensión. La pasta es tosca de color marrón con un grosor de 0,61 cm y abundantes desgrasantes de calcita, chamota y mica. Cocción «tipo C». Esta pieza está realizada a torno lento, con la superficie externa alisada y decorada con tres líneas incisas horizontales y paralelas en la parte superior de la carena.

En general, esta olla está muy bien representada en el interior de la Península Ibérica, con una cronología que abarca desde siglo vir d.C. al IX d.C. (Gutiérrez 1996, 81). En el valle medio del Ebro se encuentran este tipo de vasijas en contextos de mediados del siglo viII d.C. (Hernández y Bienes 2003, 313, fig. 3, 4).

\subsubsection{Olla, inv. n. ${ }^{\circ} 12.36 .824$ (fig. 3, n.o 4; lám. I, n. ${ }^{\circ} 4$ )}

Olla o marmita de cuerpo hiperboloide con una altura de $14,5 \mathrm{~cm}$, boca de $10,7 \mathrm{~cm}$ de diámetro, borde exvasado, labio redondeado y cuello curvo. La base es plana de $8,5 \mathrm{~cm}$ de diámetro y no se ha observado ningún tipo de suspensión. La pasta es tosca de color marrón con un grosor de $0,41 \mathrm{~cm}$ y abundantes desgrasantes de calcita, chamota y mica. Cocción «tipo C«. Esta pieza está realizada a torno lento, con la superficie externa alisada y sin decoración.

Como se ha dicho con anterioridad este tipo de ollas globulares de boca ancha y sin ninguna clase de suspensión está muy bien representado en el interior de la Península Ibérica y es una forma muy común en todos los registros cerámicos de cronología altomedieval.

\subsubsection{Olla, inv. n. ${ }^{\circ} 12.36 .830$ (fig. 3 , n. $^{\circ}$ 2)}

Olla o marmita de forma globular con una altura de $19,5 \mathrm{~cm}$, boca de $13 \mathrm{~cm}$ de diámetro, borde curvo y exvasado, labio con acanaladura central y cuello corto y curvo. La base es ligeramente abombada e irregular sin aristas bien definidas, de $12 \mathrm{~cm}$ de diámetro y no tiene ningún tipo de suspensión. La pasta es tosca de color gris con un grosor de $0,5 \mathrm{~cm}$ y abundantes desgrasantes de sílice, caliza, chamota y mica. Cocción «tipo B». En la línea de unión de la base con el cuerpo se observan improntas digitales que indican un tipo de factura mixta. La superficie externa ha sido alisada y carece de decoración.

Se han documentado ollas de características similares en Mérida, fechadas entre los siglos vi y viII d.C. (Alba y Feijoo 2003, 489 y 495). También se han encontrado paralelos en el grupo cerámico de la clase «TL 2» de los yacimientos de Gózquez, La Indiana y Fuente de la Mora (Madrid) que ha sido datado entre el siglo viI d.C. y la primera mitad del siglo viII d.C. (Vigil-Escalera 2003, 378 y 380). En el valle medio del Ebro se han documentado vasijas de este tipo, con una pequeńa acanaladura en el labio, en contextos de mitad del siglo viII d.C. (Hernández y Bienes 2003, 313, fig. 5.1).

\subsubsection{Olla, inv. n. ${ }^{0} 12.36 .498$ (fig. 3 , n. $^{\circ}$ 6; lám. I, n.o 5 )}

Olla o marmita de forma globular con hombros poco marcados, boca amplia de $13 \mathrm{~cm}$ de diámetro, borde vertical, labio redondeado y cuello corto y curvo. No tiene ningún tipo de suspensión. Pasta tosca de color salmón con un grosor de $0,58 \mathrm{~cm}$ y abundantes desgrasantes de caliza, chamota y mica. Cocción «tipo A». La pieza está realizada mediante la utilización de un torno lento o torneta y decorada con carenas irregulares dispuestas en posición horizontal. 
Las piezas de cuerpo ovoide, hombros poco marcados y acabados acanalados asociadas a barros de tonalidades claras son comunes entre la cerámica islámica de primera época. En el valle medio del Ebro se encuentran ollas con dichas características en contextos de principios del siglo IX, aunque estas vasijas están asociadas a bordes vueltos y mucho más complejos. Por otro lado, en el yacimiento de La Solana (Cubelles, Barcelona) existen ollas cocidas en ambiente reductor pero con características muy similares a ésta, datadas entre los siglos $\mathrm{v}$ d.C.-vir d.C. (López et al. 2003, 50).

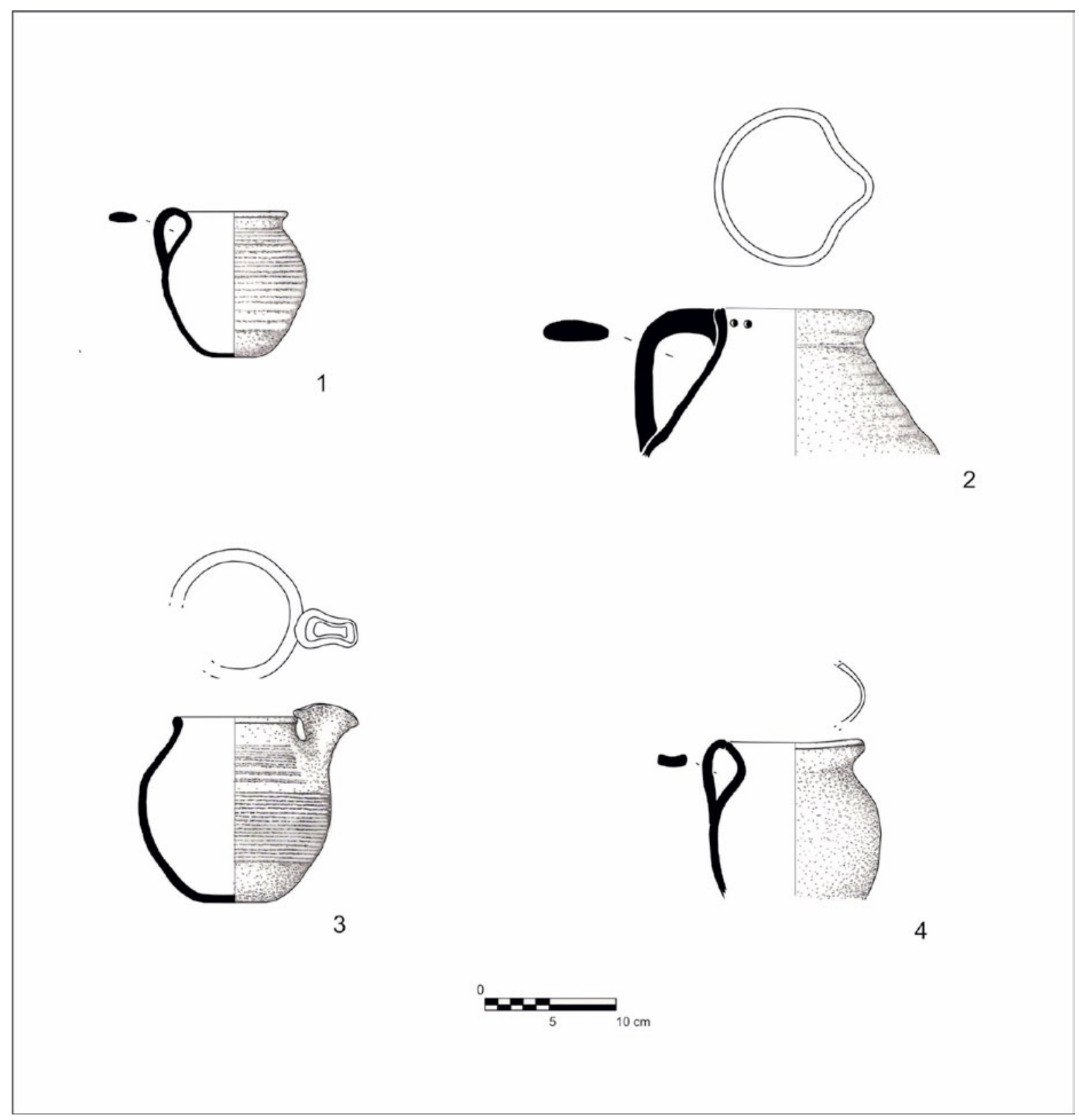

Figura 5 


\subsection{Jarro}

Con esta denominación se identifican a recipientes de tamaño medio (entre 10 y $25 \mathrm{~cm}$ ) con boca amplia, con o sin vertedor, y asa, empleados principalmente para el servicio y consumo de líquidos aunque también pueden destinarse a funciones culinarias. La excavación de la cocina ha permitido recuperar un total de cuatro jarros, que tienen en común la forma ovoide del cuerpo, el cuello corto y curvo y el labio exvasado. Dos de ellos presentan un pico vertedor en forma de pellizco y otro posee un caño independiente del cuerpo que recuerda a los «cuencos con pitorro» de tradición tardorromana (Vegas 1973, 38). Las bases que se han conservado son planas y las suspensiones tienen forma de cinta o de sección ovalada y nacen en el borde de la pieza.

En general, la morfología de las piezas invita a pensar que se trata de objetos que pudieron estar destinados a la contención de líquidos, bien sea para su servicio, como es el caso del jarro inv. n. ${ }^{\circ} 12.36 .697$, o bien sea con una función culinaria, para cocer, calentar y consumir líquidos, como podrían evidenciar las huellas de uso causadas por una exposición prolongada al fuego sobre la pared opuesta a la zona donde probablemente estuvo el asa, como se evidencia en las vasijas inv. n. ${ }^{\circ} 12.36 .823$ y en el jarro inv. n. ${ }^{\circ} 12.36 .829$. En este caso, este tipo de recipientes no se colocaban sobre el fuego sino cerca de él con el fin de que las llamas caldeasen su contenido. Esta doble función se ha documentado en recipientes de características y cronología similares procedentes de La Cora de Tudmir (Gutiérrez 1996, 71, 112-113).

La dispersión de los restos cerámicos en la habitación es desigual. Los restos procedentes del jarro inv. n. ${ }^{\circ}$ 12.36.697 aparecieron al Sur, concentrados en las columnas H e I. Por el contrario, el recipiente inv. n. ${ }^{\circ}$ 12.36.566 se encontró cerca del muro Este, en el cuadro G5. También cerca del muro Este se localizó la vertedera (inv. n. ${ }^{\circ}$ 12.36.823). Por último, en el ángulo NW se encontró la vasija inv. n. ${ }^{\circ} 12.36 .829$ (fig. 6).

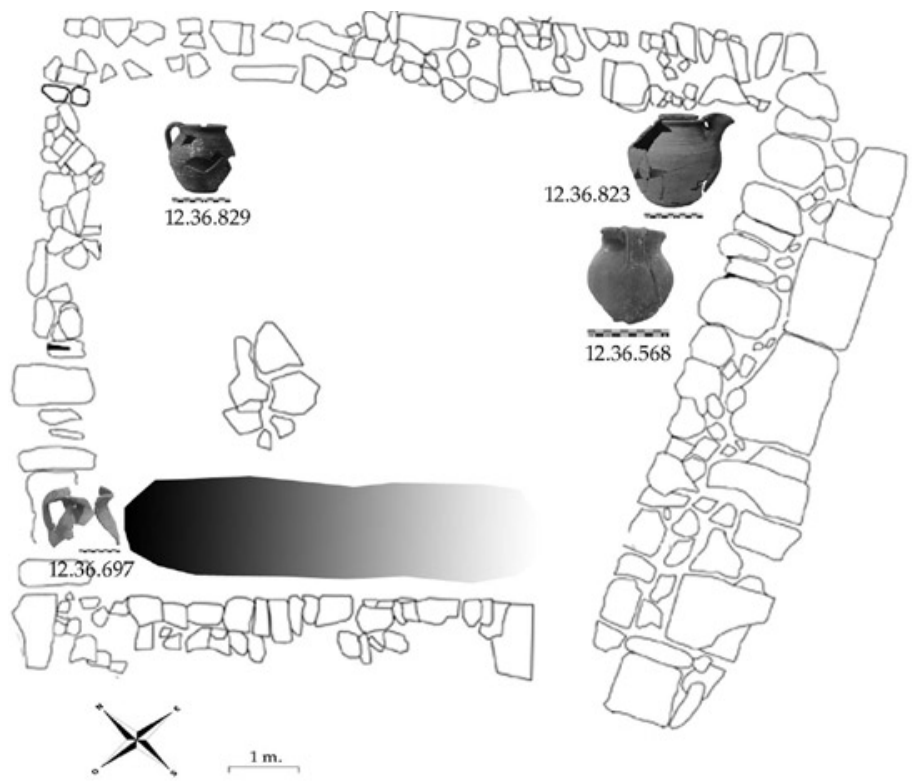

FIgura 6. Distribución (aproximada) de los restos recuperados en $A 4$ 


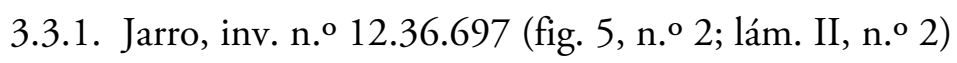

Jarro de cuerpo ovoide con boca trilobulada y amplia de 12,02 cm de diámetro, borde curvo y exvasado, labio con acanaladura central, pico vertedor de pellizco y cuello corto y curvo con dos líneas finas paralelas a modo de decoración. Tiene un asa vertical de cinta que parte del borde opuesto a la vertedera y se apoya en la zona más saliente del cuerpo. No se conserva la base. La arcilla con la que se ha realizado la pieza es tosca y de color gris con un grosor de $0,48 \mathrm{~cm}$ y abundantes desgrasantes de calcita. Cocción «tipo B». La factura se ha realizado con un torno lento y el acabado externo mediante el uso de una espátula. Tiene ligeras acanaladuras muy anchas en la zona superior del galbo.

Los fragmentos cerámicos recuperados no aparecen relacionados con el hogar y las huellas producidas por la acción del fuego no indican un uso culinario sino que son la evidencia del incendio que destruyó la estancia. Se ha observado la presencia de dos perforaciones circulares de $1 \mathrm{~cm}$ de diámetro en la zona superior de la vasija, entre el cuello y el borde, realizadas con posterioridad a la cocción. Estos orificios podrían identificarse como lañas de reparación, como prueba su equidistancia respecto a una fractura anterior. El lañado de los vasos denota el intento de prolongar al máximo la vida del recipiente, no siendo de extrañar que estas prácticas se generalizasen en momentos en que el suministro regular de vajilla cerámica encuentra dificultades. De todas formas, tampoco puede descartarse del todo la habilitación de algún dispositivo de cierre.

Teniendo en cuenta estos datos es posible concluir que la pieza estuvo destinada al servicio y contención de líquidos.

Los jarros de cuerpo ovoide, borde exvasado, pico vertedor de pellizco y pasta gris comienzan a aparecer a finales del siglo vi d.C. y principios del viı d.C. En Valencia y Barcelona existen vasijas con las mismas características fechadas en estos siglos (Pascual et al. 2003, 104; López et al. 2003, 45-49). También se han encontrado paralelos en el grupo cerámico de la clase «TL 2» de algunos yacimientos de Madrid que han sido datados entre el siglo viI d.C. y la primera mitad del siglo viII d.C. (Vigil-Escalera 2003, 380). En el valle medio del Ebro se han documentado vasijas de este tipo a lo largo del siglo viII d.C. (Hernández y Bienes 2003, 310-311).

\subsubsection{Jarro, inv. n. ${ }^{\circ} 12.36 .566$ (fig. 5 n n. $^{\text {o }}$ )}

Jarro de cuerpo ovoide con una boca trilobulada y amplia de $11 \mathrm{~cm}$ de diámetro, borde curvo y exvasado, labio biselado hacia el exterior en el que se observa una pequeña acanaladura central, pico vertedor de pellizco y cuello corto y curvo. Tiene un asa vertical de cinta que parte del borde opuesto a la vertedera y se apoya en la zona más saliente del cuerpo. No se conserva la base. La pasta es tosca y de color gris con un grosor de $0,5 \mathrm{~cm}$ y abundantes desgrasantes de mica, sílice, calcita y caliza. Cocción «tipo B». La factura se ha realizado con un torno lento y para el alisado de la superficie externa se ha utilizado una espátula. No tiene ningún tipo de decoración.

Por desgracia, no se puede determinar si esta pieza tuvo un uso culinario o si únicamente se utilizó como servicio y contención de líquidos ya que todos los fragmentos aparecieron quemados en su totalidad.

Como se ha apuntado en la descripción de la pieza anterior, esta tipología de jarros está muy extendida por la Península Ibérica desde finales del siglo vi d.C. hasta mediados del siglo vin d.C. En los inicios del siglo IX d.C. existen vasijas de cuerpo ovoide con asa de cinta y pico vertedor de pellizco pero están elaboradas a torno y las cocciones son de tipo oxidante o «tipo C». 
3.3.3. Jarro, inv. n.o 12.36 .823 (fig. 5, n. o 3; lám. II, n. o 3)

Jarro de cuerpo globular con una altura de $15,5 \mathrm{~cm}$. La boca mide $10 \mathrm{~cm}$ de diámetro y está formada por un borde curvo y exvasado de labio engrosado y redondeado. El cuello es corto y curvo. Tiene un pitorro vertedor corto y de forma tubular separado del borde y aplicado a la pared de la vasija. La base es plana y tiene una dimensión aproximada de $9,5 \mathrm{~cm}$ de diámetro. No se ha conservado ningún tipo de suspensión. La pasta es tosca y de color marrón con un grosor de 0,62 cm y desgrasantes de caliza, chamota y mica. Cocción «tipo C». Esta pieza está realizada a torno lento y decorada con bandas incisas y paralelas que cubren la totalidad de la superficie externa.

Aunque este tipo de jarros con vertedor tubular podrían tener su precedente morfológico en la cerámica común tardorromana, en Valencia se han documentado recipientes con pitorro vertedor cilíndrico, corto y sobreelevado, de pastas toscas y cocciones oxidantes, en contextos de los siglos VI d.C. y vir d.C. (Pascual et al. 2003, 105-106). También se han encontrado paralelos en el grupo cerámico de la clase «TL 2» de algunos yacimientos madrileños fechados entre el siglo vil d.C. y la primera mitad del siglo viII d.C., aunque ya en el siglo vi d.C. aparece esta misma forma elaborada a torno (Vigil-Escalera 2003, 380-383). Dentro del mismo ámbito cronológico hay jarros con caño vertedor independiente realizados a torno lento en Aguilar del Río Alhama (La Rioja) (Hernández y Bienes 2003, 308-310).

\subsubsection{Jarro, inv. n. ${ }^{\circ} 12.36 .829$ (fig. 5 , n. $^{\circ} 1$; lám. II, n. ${ }^{o} 1$ )}

Jarro de forma globular con una altura de $12,2 \mathrm{~cm}$. La boca mide $8 \mathrm{~cm}$ de diámetro y está formada por un borde exvasado de labio redondeado desde donde parte un asa vertical de cinta que se apoya en la zona más saliente de la panza. El cuello es corto y curvo y la base plana de $4,5 \mathrm{~cm}$ de diámetro. La pasta es tosca y de color marrón con un grosor de 0,40 cm y desgrasantes de caliza, chamota y mica. Cocción «tipo C». Esta pieza está realizada a torno lento y decorada con acanaladuras paralelas que cubren la totalidad de la superficie externa.

Jarros con características similares se han documentado en los yacimientos de El Zambo (Novelda, Alicante), Cabezo de Molino (Rojales, Alicante), Puig Rom (Gerona) y en el Castelo Velho de Alcoutim (Portugal) fechados en torno a los siglos viII d.C. y ix d.C. (Gutiérrez 1996, 112-113).

\subsection{Botellalánfora}

En general, las botellas/ánforas son recipientes de tamaño medio (entre 10 y $25 \mathrm{~cm}$ ) caracterizados por tener un cuello largo y estrecho y una o dos asas. Normalmente se emplean para el transporte y servicio de líquidos aunque también son aptos para escanciar líquidos o contener ungüentos (Roselló Bordoy 1991, 165), hecho confirmado por la ausencia de indicios de fuego. La excavación de la cocina ha permitido la identificación de cinco ejemplares, aunque en un gran estado de fragmentación.

La primera de ellas (inv. n. ${ }^{\circ}$ 12.36.826) se encontró en las cercanías del muro Oeste de la habitación, entre los cuadros G1-H1, si bien su grado de dispersión hacia H2 invita a considerar que cayó desde una cierta altura. En el ángulo NW se localizó la botella ovoide inv. n. ${ }^{0}$ 12.36.815. En ese mismo lado de la habitación se encontró el único resto conservado de la vasija inv. n. ${ }^{\circ}$ 12.36.473. Por último, los dos fragmentos conservados del recipiente inv. n. ${ }^{\circ} 12.36 .682$ se encontraron en el centro del muro Este (fig. 7). 


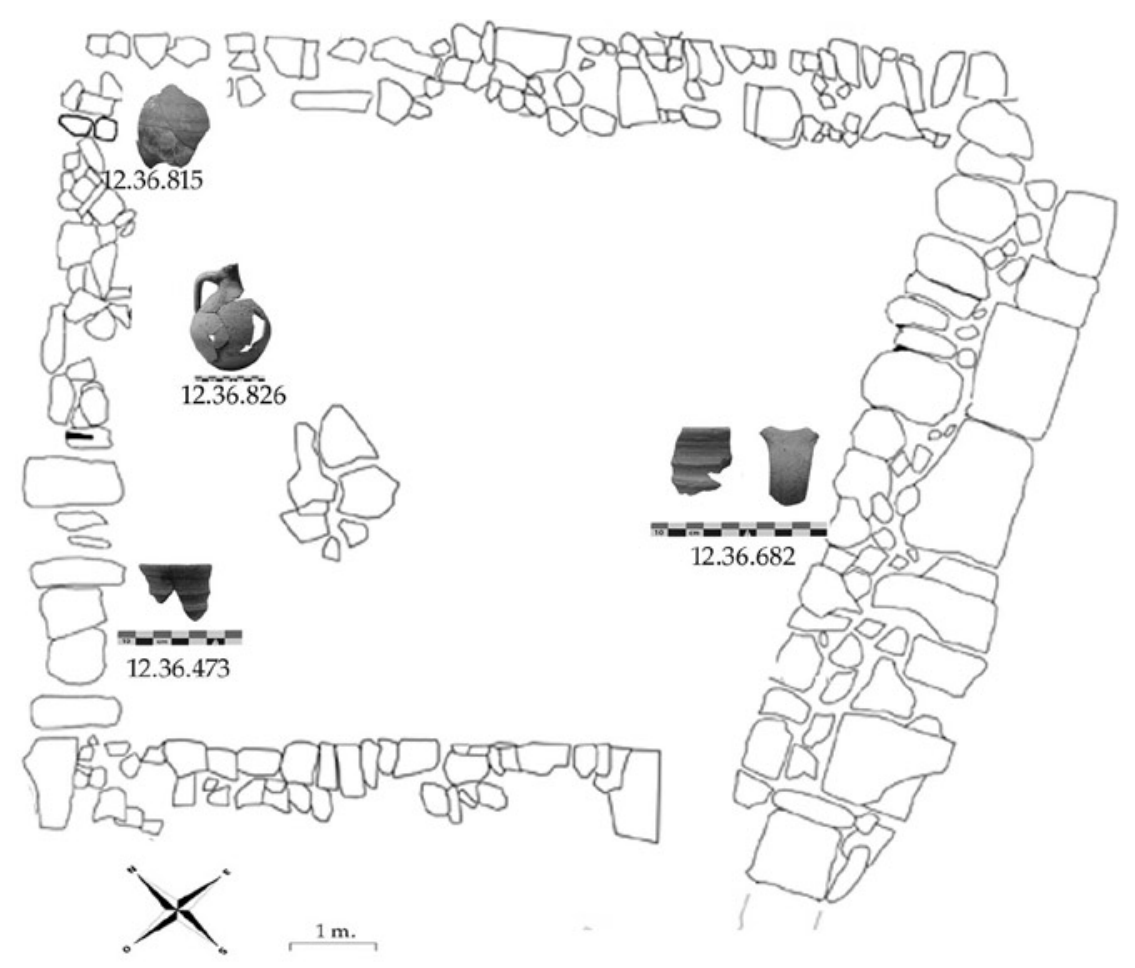

Figura 7. Distribución (aproximada) de los restos recuperados de botellaslánforas en $A 4$

\subsubsection{Botella, inv. n.o 12.36 .826 (fig. 8, n.o 1; lám. III, n. ${ }^{\circ}$ 1)}

Botella de tamaño medio con forma de pera, cuello estrecho, asa vertical de sección ovalada que parte de la zona media del cuello y se apoya en la zona más saliente del cuerpo y fondo plano sin aristas definidas, de unos $8 \mathrm{~cm}$ de diámetro. La pasta es tosca, de color anaranjado, con un grosor de 0,41 cm y desgrasantes de calcita, sílice y mica. Cocción «tipo C». La factura se realizó mediante el uso de un torno lento con alisado externo y tiene varias bandas incisas y paralelas en la parte superior del galbo a modo de decoración.

Este tipo de botellas son bastante frecuentes en el mundo funerario de época visigoda del siglo viI d.C., como ejemplifica la encontrada en la necrópolis de l'Almoina (Valencia), fechada entre los siglos vir y viII d.C. (Pascual et al. 2003, 82-83). De todas formas, también se conocen en otros ámbitos como en el yacimiento de Los Pontones (Albacete) donde se encontraron recipientes similares pero sin suspensiones, en contextos del siglo viI d.C. (Gutiérrez 1996, 105-106). En el mismo espacio cronológico se integran las botellas con dos asas de Vistalegre (Aspe, Alicante) y Orihuela (Alicante) realizadas a torno (Gutiérrez 1996, 105-107). También existen piezas morfológicamente similares en el yacimiento de La Cabeza (Navasangil, Ávila) con un amplio espectro cronológico que abarca desde el siglo vi al viII d.C. (Larrén et al. 2003, 295 y 299). Por último, en Zaragoza se localizó un ejemplar de este tipo que data de mediados del siglo viII d.C. (Hernández y Bienes 2003, 310-313). 
3.4.2. Botella, inv. n.o 12.36 .739 (fig. 8, n.o 4; lám. III, n.o 4)

Fragmento de botella de cuello estrecho y corto, boca de $3,18 \mathrm{~cm}$ de diámetro, borde exvasado y labio engrosado en forma de visera. La pasta es tosca, de color beige, con un grosor de $0,60 \mathrm{~cm}$, y desgrasantes de calcita, sílice, mica y chamota. Cocción «tipo C». Esta pieza está realizada a torno lento con alisado externo y no se ha observado ningún tipo de decoración.

No hay indicios de fuego y por sus características morfológicas resulta adecuado para el servicio de líquidos. Es posible que se trate de una evolución tipológica de la forma «Gosse, 1950, 376» de cerámica común romana (Beltrán 1990, 199, fig. 96 n. ${ }^{\circ}$ 880). Recipientes de características similares se han documentado en Zaragoza en contextos de mediados del siglo viII d.C. (Hernández y Bienes 2003, 310-313).

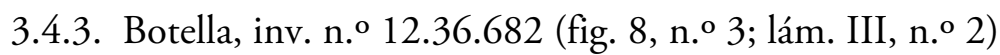

Fragmento de botella o ánfora de cuello y borde vertical, exvasado y acanalado y labio biselado hacia el interior del que parte un asa de sección ovalada. Boca de 6,6 cm de diámetro. Pasta tosca de color salmón con un grosor de $0,45 \mathrm{~cm}$ y desgrasantes de calcita y mica. Cocción «tipo C». La pieza está realizada a torno lento y decorada con numerosas acanaladuras.

Por el momento no se han encontrado paralelos para este tipo de pieza. Sus características morfológicas invitan a pensar que quizá podría tener su origen tipológico en la Forma II fabricada en el alfar de Tarazona en época romana altoimperial (Aguarod 1985, 75-76, fig. 16 n. ${ }^{\circ}$ 64). Por otra parte, también se asemeja, de forma muy general, a ciertas ánforas hispánicas cuya producción final se encuadra entre los siglos vi y vir d.C. No obstante, dada la ausencia de paralelos, es probable que se trate de una producción local realizada en algún momento de la segunda mitad del siglo viII d.C.

\subsubsection{Botella, inv. n. ${ }^{\circ} 12.36 .473$ (lám. III, n.o 3)}

Fragmento de botella o ánfora de cuello y borde vertical, exvasado y acanalado y labio biselado hacia el interior. No se ha conservado el asa. Boca de 6,6 cm de diámetro. Pasta tosca de color salmón con un grosor de $0,45 \mathrm{~cm}$ y desgrasantes de calcita y mica. Cocción «tipo C». La pieza está realizada a torno lento y decorada con numerosas acanaladuras. Existen pequeños indicios de fuego que no parecen tener relación con la vida útil del recipiente.

Esta pieza es similar a la descrita anteriormente, aunque en este caso no se ha conservado el asa.

\subsubsection{Botella, inv. n. ${ }^{\circ} 12.36 .815$ (fig. 8, n. $^{\circ} 2$ )}

Fragmento de botella o ánfora de forma ovoide decorada con una banda ondulada incisa en la parte superior del galbo. La arcilla es tosca, de color gris, con un grosor de $0,53 \mathrm{~cm}$ y desgrasantes de calcita y mica. Cocción «tipo A». La factura se realizó mediante un torneado lento y posteriormente se alisó la superficie externa con una espátula.

Recipientes similares se han encontrado en el relleno de amortización de un pozo del yacimiento de l'Almoina (Valencia), con fecha de finales del siglo vi e inicios del vil d.C. (Pascual et al. 2003, 75-76). 


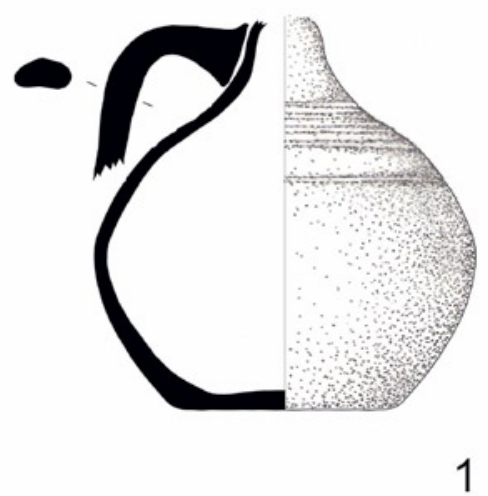

1

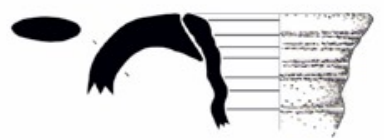

3

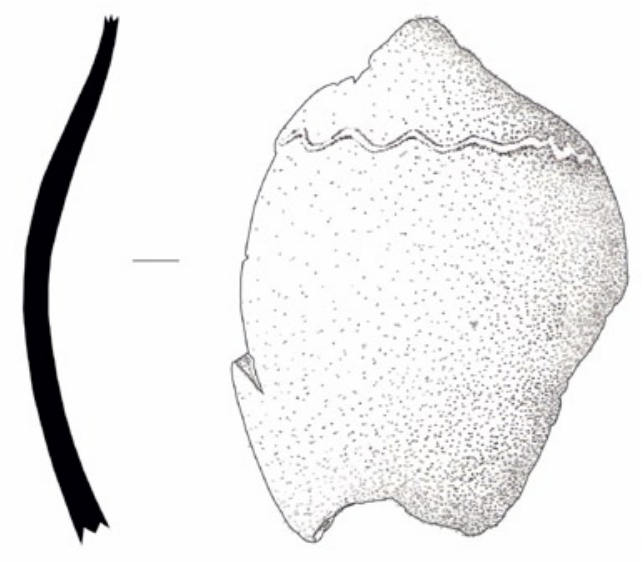

2

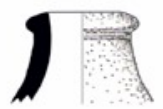

4

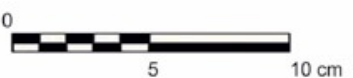

Figura 8. Botellas/ánforas

\subsection{Cerámica de transporte y almacenaje (tamaño medio)}

En general, se trata de recipientes de tamaño medio (entre 15 y $30 \mathrm{~cm}$ de altura) con boca estrecha, sin asas, fondo plano y elaborados con arcillas sin depurar con numerosos desgrasantes. Las medidas y características técnicas y morfológicas de estas tinajas hacen que sean aptas para el transporte y/o al almacenaje tanto de líquidos (agua, aceite, vinagre, vino) como de sólidos (grano, legumbres, encurtidos, etc.).

La excavación de la cocina ha permitido el descubrimiento de dos piezas, cuyos fragmentos muestran una gran dispersión por la habitación. A pesar de ello, durante la excavación se apreció una cierta concentración de restos pertenecientes a la primera (inv. n. ${ }^{\circ} 12.36 .825$ ) en el cuadro G5, mientras que los restos de la segunda (inv. n. ${ }^{\circ}$ 12.36.828) muestran una dispersión en forma de cuña, desde el ángulo NE y centro del muro Norte hacia el Oeste.

\subsubsection{Tinaja, inv. n. ${ }^{\circ} 12.36 .825$ (fig. 9, n. o 3; lám. IV, n. ${ }^{\circ}$ 3)}

Tinaja de 17,4 cm de altura, cuerpo de tendencia ovoide, sin asas, boca de $8 \mathrm{~cm}$ de diámetro, borde curvo y exvasado de labio redondeado, cuello corto y fondo plano de $10,5 \mathrm{~cm}$ de diámetro. La pasta es tosca, de color marrón, con un grosor de 0,61 cm y desgrasantes de caliza, mica y cha- 
mota. Cocción «tipo C». Factura a torno lento con alisado en la pared interna y presencia de acanaladuras en la zona media y superior de la superficie externa que facilitan su manejo.

Los fragmentos cerámicos están muy quemados pero no aparecen relacionados con el hogar y las huellas producidas por la acción del fuego no indican un uso culinario sino que bien pueden ser consecuencia del incendio que destruyó la estancia. Debido a su tamaño medio se trata de un recipiente apto para el transporte y/o almacenaje de líquidos y sólidos.

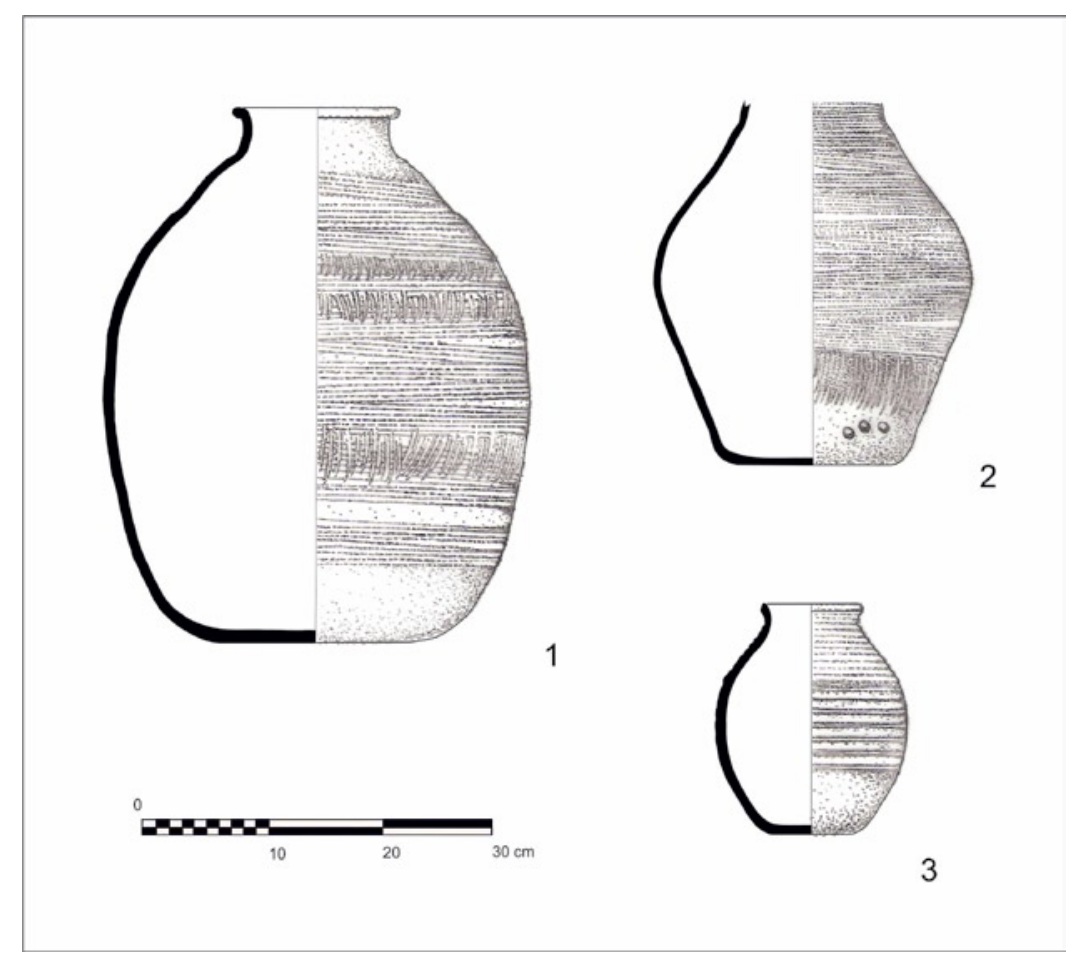

FIgURA 9. Cerámica de transporte y almacenaje (tamaño medio)

Debido al carácter doméstico de estos recipientes por el momento no se han encontrado paralelos en otros yacimientos.

\subsubsection{Tinaja inv. n. ${ }^{\circ} 12.36 .828$ (fig. 9 n n. $^{\circ} 2$; lám. IV, n.o 2)}

Tinaja incompleta de $28,5 \mathrm{~cm}$ de altura, cuello de $10,3 \mathrm{~cm}$ de diámetro, cuerpo de tendencia ovoide, sin asas, con una carena en la zona media del galbo y fondo plano de $16,5 \mathrm{~cm}$ de diámetro. Pasta tosca de color marrón con un grosor de $0,60 \mathrm{~cm}$ y desgrasantes de caliza, mica y chamota. Cocción "tipo A». Factura a torno lento o torneta, alisado interno y decoración con bandas incisas horizontales y oblicuas intercaladas.

Los fragmentos cerámicos tienen huellas de fuego producidas por un incendio. Además, se ha observado la existencia de numerosas perforaciones circulares de $1 \mathrm{~cm}$ de diámetro en la base y en la zona inferior del cuerpo realizadas con posterioridad a la cocción de la pieza y que tal vez se traten de lańas de reparación. Estos orificios inutilizaron la tinaja como contenedor de líqui- 
dos por lo que pudo usarse para el transporte y almacenaje de sólidos (grano, encurtidos, legumbres, etc.).

En Aguilar del Río Alhama (La Rioja) se han encontrado tinajas de almacenaje, sin decorar, de similares características morfológicas fechadas a finales del siglo vil d.C. (Hernández y Bienes 2003, 310).

\subsection{Cerámica de almacenaje (gran tamaño)}

En general, se trata de recipientes de tamaño grande (entre 30 y $60 \mathrm{~cm}$ de altura) con boca estrecha, sin asas, fondo plano y paredes gruesas de arcilla sin depurar. Las características técnicas y morfológicas de estas tinajas y su gran tamańo hacen que sean aptas para el almacenaje y conservación tanto de sustancias líquidas (agua, aceite, vinagre, vino) como sólidas (grano, legumbres, encurtidos, etc.). La excavación ha permitido localizar un ejemplar dividido en 92 fragmentos, concentrados en su mayor parte en la mitad del muro Sur.

\subsubsection{Tinaja inv. n. ${ }^{\circ} 12.36 .822$ (fig. 9 , n. $^{o} 1$; lám. IV, n. ${ }^{\circ}$ 1)}

Tinaja de $41 \mathrm{~cm}$ de altura, cuerpo de tendencia ovoide, sin asas, cuello corto, boca de $13,5 \mathrm{~cm}$ de diámetro, labio exvasado con borde engrosado y redondeado y fondo plano de $22,5 \mathrm{~cm}$ de diámetro. La pasta es tosca, de color marrón, con un grosor de $0,62 \mathrm{~cm}$ y desgrasantes groseros de caliza, mica y chamota. Cocción «tipo A». La factura se ha realizado por medio de un torno lento con alisado posterior tanto en la pared interna como en la externa del recipiente y presenta decoración de bandas incisas horizontales y oblicuas intercaladas.

Para el modelado de grandes tinajas se utilizaba la ejecución por tiempos, es decir, se elaboraba la pieza por partes dejando secar cada una antes de acoplarlas para que la sección inferior pudiese resistir el peso. Posteriormente se aplicaban cordones en relieve para reforzar las juntas de unión (Gutiérrez 1992, 362). Sin embargo, la pieza que procede de El Pueyo no presenta indicios de acoplamiento por lo que pudo realizarse mediante un torneado lento y discontinuo que permitiese el endurecimiento de la arcilla.

\section{CerÁmica fina}

El grupo de materiales denominado «cerámica fina» está representado por cinco piezas, tres asas y dos bordes, realizadas a torno y cubiertas por engobes de diferentes tonalidades aplicados tanto en el interior como en el exterior de la superficie. La arcilla es dura, compacta y homogénea, de colores claros que van desde el beige hasta el rojizo pasando por tonos rosados y anaranjados lo que indica que los cinco ejemplares fueron sometidos a un proceso de cocción en atmósfera oxidante. Los desgrasantes apenas son visibles y únicamente se pueden distinguir pequeños puntos calcíticos $\mathrm{y}$, en algunos casos, cristales de cuarzo.

Desde un punto de vista tipológico y funcional todos los recipientes estuvieron destinados al servicio de mesa y morfológicamente son de clara tradición romana (Aguarod 1985, 39-91). En este sentido, pese a la cronología tardía de la cocina, no es extraño que en ocasiones aparezcan cerámicas «residuales» de vajilla fina de épocas anteriores en contextos de los siglos viI y viII d.C. Así, en Mérida se han encontrado fragmentos de terra sigillata clara en contextos estratigráficos del siglo VIII d.C., lo que indica «el valor que debieron concederles sus últimos usuarios a estas piezas transmiti- 
das generacionalmente» (Alba y Feijoo 2003, 489). Asimismo hay que destacar que existieron dos alfares que en época romana altoimperial abastecieron de cerámica engobada a todo el valle medio del Ebro dentro del ámbito geográfico en el que se enmarca este conjunto arqueológico, situados en Ejea de los Caballeros y en Tarazona (Aguarod 1985, 27-106; Aguarod y Amaré 1987, 841-861).

Por desgracia, la mayor parte de los recipientes se encuentran muy perdidos por lo que son muy pocos los fragmentos recuperados y no se puede realizar un estudio de dispersión en la cocina que represente la realidad de aquel momento. En cualquier caso, conviene destacar que tres de ellos (inv. n. ${ }^{\circ}$ 12.36.422.1; 425; y 528) se han encontrado en las cercanías de la puerta de entrada, mientras que el cuarto (inv. n. ${ }^{\circ}$ 12.36.698.4) apareció en el ángulo NE y el último (12.36.589) en la criba.

\subsection{Jarralbotella, inv. n. ${ }^{\circ} 12.36 .589$ (lám. V, n.o 1)}

Fragmento de asa de 1,38 cm de grosor con una acanaladura central muy marcada que recorre longitudinalmente la superficie exterior, dando lugar a dos molduras. Presenta restos de engobe mate de color marrón. La pasta es compacta y homogénea, de color beige-anaranjado, con pequeños desgrasantes de calcita y cuarzo. Cocción reductora con post-cocción oxidante «tipo A». Esta pieza pudo pertenecer a una jarra o botella destinada al servicio y contención de líquidos y se asemeja a la cerámica engobada de época romana altoimperial procedente del alfar de Turiaso (Tarazona) (Aguarod 1985, 90-91, fig. 23, n. ${ }^{\circ}$ 97).

\subsection{Jarralbotella, inv. n. ${ }^{\circ} 12.36 .422 .1$ (lám. V, n.o 2 )}

Fragmento de asa engobada en tonos rojizos de $1,1 \mathrm{~cm}$ de grosor con tres acanaladuras muy marcadas que recorren longitudinalmente la superficie exterior, dando lugar a cuatro molduras. La pasta es compacta y homogénea de color anaranjado y con desgrasantes de calcita. Cocción oxidante «tipo C». Esta pieza, al igual que la descrita con anterioridad (inv. n. ${ }^{\circ}$ 12.36.589), pudo pertenecer a una jarra o botella destinada al servicio y contención de líquidos y también tiene similitud con la cerámica engobada de época romana altoimperial (Aguarod 1985, 90-91, fig. 23 n. ${ }^{\text {9 } 94) .}$

\subsection{Jarritalvaso, inv. n.o 12.36.698.4 (lám. V, n.o 3)}

Fragmento de asa vertical de sección circular con un diámetro de $0,91 \mathrm{~cm}$ y engobe mate en tonos anaranjados. La pasta es compacta y homogénea de color rojizo y con desgrasantes de calcita. Cocción oxidante «tipo C». Esta pieza pudo formar parte de una jarrita o un vaso destinado al servicio y contención de líquidos y por sus características técnicas recuerda a la cerámica engobada de época romana altoimperial (Beltrán 1990, 289-291).

\subsection{Cuencolvaso, inv. n.o 12.36.475 (lám. V, n.o 4)}

Fragmento de borde recto y exvasado con labio apuntado perteneciente a un cuenco o vaso con engobe aplicado por la superficie externa e interna de la pared, de color marrón-rojizo. La pasta es compacta y homogénea de color anaranjado con un grosor de $0,49 \mathrm{~cm}$ y pequeños desgrasantes de calcita. Cocción oxidante «tipo C». La pieza estuvo destinada, probablemente, a la contención de líquidos y se asemeja a la cerámica engobada de época altoimperial (Beltrán 1990, 289-291). 
4.5. Olla, inv. n. ${ }^{o} 12.36 .528$ (lám. V, n.o 5)

Fragmento de una olla globular con borde exvasado, labio engrosado de sección redondeada, boca de 13,2 cm de diámetro y cuello corto y curvo. Pasta compacta y homogénea de color rosáceo con un grosor de $0,5 \mathrm{~cm}$ y desgrasantes de calcita y cristales de cuarzo. Cocción oxidante «tipo C». La superficie externa está decorada con carenas y tiene restos de engobe mate en tono rojizo-marón. No se han observado huellas de uso. Los modelos en los que se ha basado el alfarero para realizar esta pieza son formas pertenecientes al mundo de la cerámica común romana engobada (Aguarod 1985, 54-55).

\section{Conclusiones}

A modo de conclusión, son diversos los aspectos a señalar de este conjunto cerámico. Así, primero, puede considerarse que a partir del estudio detallado del material cerámico procedente de A4 se puede inferir que la mayor parte de las piezas comparten características con la cerámica registrada en yacimientos de la Península Ibérica pertenecientes a los siglos viI y viII d.C. Se ha observado que existe un predominio casi absoluto de producciones locales destinadas a la preparación culinaria y al almacenaje de líquidos y sólidos. Por el contrario, son muy pocas las piezas destinadas al uso directo, como platos o vasos, pues tan sólo se ha podido identificar un ejemplar (inv. n. ${ }^{\circ}$ 12.36.475). En este sentido, no cabe duda de que se ha perdido parte de esta vajilla de uso diario que, posiblemente, se empleó en la casa, quizá porque pudo haber estado hecha en madera.

En general, las piezas conservadas están elaboradas con pastas toscas, sin depurar y con una presencia abundante de desgrasantes de calcita, mica y chamota. Las superficies externas están alisadas mediante la técnica del espatulado y en ocasiones se observan evidencias de bruñido. Por otro lado, se constata la existencia de un grupo de cerámica fina engobada dentro del contexto de los materiales cerámicos de El Pueyo que puede considerarse como puramente residual. No obstante, creemos que hay que tener presente la importancia que supone la aparición de este tipo cerámico en fechas tan avanzadas y en el área geográfica analizada.

Por otro lado, segundo, se aprecia un dominio del uso de «torneta» o torno lento en la factura de las piezas. Predominan las vasijas asimétricas con estrías irregulares en la pared interna y bases rugosas que evidencian el empleo de arena como medio para evitar la adherencia con la superficie de la rueda. Los recipientes con fondos convexos tienen un sistema de modelado mixto: por un lado se elabora la base de forma manual y posteriormente se une al resto de la vasija fabricada previamente mediante un torno lento. La presencia de improntas digitales en la unión de la base con el cuerpo de algunas piezas confirma el uso de esta técnica. Para el modelado de grandes tinajas se utilizó la ejecución por tiempos mediante el torneado lento e irregular de la arcilla. Con este sistema se consigue que la zona inferior de la pieza se seque y endurezca lo suficiente para soportar el peso de toda la tinaja.

Tercero, conviene resaltar la abundancia de piezas elaboradas con arcillas en tonos marrones que evidencian sistemas de cocción en atmósferas oxidantes o "tipo C». A este grupo le sigue en representación un conjunto de vasijas pertenecientes al «tipo A» con pastas de núcleo grisáceo y superficies de tonalidades marrones. También se han identificado piezas con pastas de color gris debido a una cocción reductora o «tipo $B$ » y un pequeño porcentaje de cerámicas de cocción oxidante y post-cocción reductora o «tipo D». Según los estudios realizados en los últimos años se ha observado que a lo largo del siglo vi y comienzos del viI d.C. predominan las cerámicas de coccio- 
nes reductoras (Larren et al. 2003, 277-304; López et al. 2003, 48-58), sin embargo, casi la mitad de las piezas procedentes de A4 fueron cocidas en atmósferas oxidantes. En este sentido, es posible que esta circunstancia sea consecuencia de una mejora en las técnicas alfareras a lo largo de los siglos vir y viII d.C., que tal vez pudo implicar un mayor control de los tiempos de cocción y un perfeccionamiento en el manejo de los hornos.

Cuarto, el sesenta por ciento de los fragmentos están decorados. Una de las técnicas utilizadas es la incisión de líneas onduladas o de bandas paralelas y entrecruzadas formando una especie de enrejado irregular. Este tipo de decoración está presente en vasijas desde el siglo vi. Sin embargo, el método ornamental más empleado es el estriado en forma de acanaladuras paralelas que cubren el cuerpo y la parte superior del recipiente. Este tipo de decoración acanalada asociada a barros de tonalidades claras son comunes entre la cerámica islámica de primera época (Alba y Feijoo 2003, 492; Folch 2005, 244). En el valle medio del Ebro encontramos ollas con dichas características en contextos de principios del siglo Ix (Hernández y Bienes 2003, 317 y 319), si bien estas vasijas están asociadas a bordes vueltos y mucho más complejos que los estudiados.

Por otro lado, en el Horizonte II del yacimiento arqueológico del Tolmo de Minateda, adscrito a la segunda mitad del siglo viII d.C., aparecen cerámicas similares a las que presentamos en este trabajo con decoración acanalada junto a algunos fragmentos pintados (Gutiérrez et al. 2003, 140-148).

Quinto, el repertorio formal es reducido, con preferencia por las formas cerradas y está representado por una cazuela de perfil en «S», cinco ollas globulares, cuatro jarros de diferente tipología, dos botellas, tres ánforas y tres contenedores de transporte y almacenaje de tamaño medio y grande. Los bordes suelen ser curvos y exvasados con labios redondeados, biselados y, en algunos casos, con una acanaladura central. Casi todas las piezas se caracterizan por tener fondos planos aunque existen vasijas con bases redondeadas y ligeramente abombadas hacia el exterior de forma intencionada. Los recipientes de fondo plano son más fáciles de fabricar pero al situarlos directamente sobre el fuego pueden llegar a romperse, por este motivo se suelen situar al lado de las llamas con el fin de calentar alimentos y líquidos. Sin embargo, las vasijas con fondo convexo son idóneas para cocinar alimentos en grandes cantidades ya que la forma abombada de su base permite colocarlas sobre la hoguera mediante el uso de una trébede con el fin de que la llama se reparta mejor por las paredes de la vasija.

Sexto, una de las cuestiones más difíciles de resolver ha sido determinar el carácter funcional de cada recipiente. Para este fin se ha realizado un estudio detallado de las características morfológicas y tecnológicas de cada pieza y se han observado las diferentes huellas de uso presentes en las paredes de las vasijas. Ahora bien, conviene puntualizar que muchos fragmentos aparecen alterados parcialmente como consecuencia del incendio que debió acompañar a la destrucción de la habitación, por lo cual se han basado las conclusiones en el análisis de las piezas que han proporcionado resultados fiables. Teniendo en cuenta esto, es posible concluir que el lote cerámico está formado por recipientes de tamaño medio y boca amplia idóneos para freír o cocer alimentos en grandes cantidades; jarros y botellas utilizados principalmente para el servicio y consumo de líquidos aunque, en ocasiones, podían emplearse en funciones culinarias; contenedores de boca estrecha aptos para el transporte y/o al almacenaje tanto de líquidos (agua, aceite, vinagre, vino) como de sólidos (grano, legumbres, encurtidos, etc.) y grandes tinajas de almacenaje. Por el contrario, como se ha comentado con anterioridad, frente al hallazgo de objetos vinculados con el procesamiento y conservación de los alimentos, no se han encontrado útiles, como platos y vasos, vinculados directamente con el consumo de estos comestibles. En nuestra opinión, esta situación quizá puede ser consecuencia del material en el que pudieron estar fabricados, tal vez madera que por su carácter perecedero no se habría conservado. 
Dentro de este contexto funcional llama la atención la presencia de numerosas perforaciones circulares de $1 \mathrm{~cm}$ de diámetro, tanto en la base como en la zona superior e inferior de la pared de algunos recipientes, efectuadas con posterioridad a su cocción. A través de la comparación etnográfica con cerámicas realizadas por alfareros tradicionales de principios del siglo xx, es posible plantear que estos orificios se realizaron para encajar lańas o grapas que no se han conservado y que fueron utilizadas en la reparación de las piezas fragmentadas. En algunos casos estas hendiduras inutilizaron la función inicial de la pieza si bien le proporcionaron un segundo uso para el que no fueron fabricadas inicialmente.

Séptimo y por último, en relación con la adscripción cronológica del lote cerámico (centrado entre mediados del siglo viıI d.C. y los últimos años del mismo) conviene precisar que en el Valle Medio del Ebro existen producciones similares dentro del mismo contexto cronológico, si bien a finales del siglo viII y principios del Ix d.C. comienzan a surgir nuevas tipologías realizadas a torno con pastas depuradas, bordes mucho más complejos y decoraciones mixtas. Estas características serán comunes en la cerámica de la primera mitad del siglo IX d.C. en toda la Península Ibérica, aunque por el momento no se han encontrado en la ciudad de Los Bañales (Uncastillo).

\section{Bibliografía}

Acién, M., Martínez, R., 1989, «Cerámica islámica arcaica del sureste de al-Andalus», Boletín de Arqueología Medieval 3, 123-135.

Acién, M., Castaño, J.M., Navarro, I., Salado, J.B., Vera, M., 2003, «Cerámicas tardorromanas y altomedievales en Málaga, Ronda y Morón", en: L. Caballero, P. Mateos, M. Retuerce (eds.), II Simposio de Arqueología, Mérida. Cerámicas tardorromanas y altomedievales en la Península Ibérica. Ruptura y continuidad, Madrid, Anejos de AEspA XXVIII, 411-454.

Aguarod Otal, M.C., 1985, «Avance al estudio de un posible alfar romano en Tarazona: II. Las cerámicas engobadas no decoradas», Turiaso VI, 27-106.

Aguarod, M.C., Amaré, M.a.T., 1987, «Un alfar romano de cerámica engobada común y lucernas en Tarazona (Zaragoza)", Actas del XVIII Congreso Nacional de Arqueología (Zaragoza), Zaragoza, 841-861.

Alba, M., Feijoo, S, 2003, «Pautas evolutivas de la cerámica común en Mérida en épocas visigoda y emiral», en: L. Caballero, P. Mateos, M. Retuerce (eds.), II Simposio de Arqueología, Mérida. Cerámicas tardorromanas y altomedievales en la Peninsula Ibérica. Ruptura y continuidad, Madrid, Anejos de AEspA XXVIII, 483-504.

Alba, M., Gutiérrez, S., 2009, «Las producciones de transición al Mundo Islámico: el problema de la cerámica paleoandalusí (siglos viII y Ix)», en: D. Bernal, A. Ribera i Lacomba (eds.), Cerámicas Hispanorromanas. Un estado de la cuestión, Cádiz, 585-613.

Álvarez Delgado, Y., 1989, "Cerámicas del siglo Ix de Arcávica (Cuenca)», Boletín de Arqueología Medieval 3, 109-121.

Azkárate, A., Núñes, J., Solaun, J.L., 2003, «Materiales y contextos cerámicos de los siglos vi al x en el País Vasco", en: L. Caballero, P. Mateos, M. Retuerce (eds.), II Simposio de Arqueología, Mérida. Cerámicas tardorromanas y altomedievales en la Peninsula Ibérica. Ruptura y continuidad, Madrid, Anejos de AEspA XXVIII, 321-370.

Beltrán Lloris, M., 1990, Guía de la cerámica romana. Zaragoza.

Bienes Calvo, J.J., 1987, «Introducción al estudio de la cerámica musulmana en la ciudad de Tudela», Turiaso VII, 115-158.

Bohigas, R., Andrio, J., Peñil, J., García, M., 1989, «Las cerámicas medievales no esmaltadas en las provincias de Cantabria, Palencia y Burgos», La cerámica medieval en el Norte y Noroeste de la Peninsula Ibérica. Aproximación a su estudio, León, 113-153. 
Caballero Zoreda, L., 1989, «Cerámicas de «época visigoda y postvisigoda» de las provincias de Cáceres, Madrid y Segovia", Boletín de Arqueología Medieval 3, 75-107.

Folch Iglesias, C., 2005, «La cerámica de la Alta Edad Media en Cataluña (siglos viri-IX d.C.): el estado de la cuestión», Arqueología y Territorio Medieval 12.2, 237-254.

Fuertes Santos, M.C., 2000, «La evolución de la cerámica medieval de cercadilla, Córdoba. Estado de la cuestión", Anales de Arqueología Cordobesa 11, 217-232.

Galve, P., 1988, "Aproximación al estudio de la cerámica de época emiral en la ciudad de Zaragoza», Caesaraugusta 65, 235-261.

Gutiérrez Lloret, S., 1992, El tránsito de la antigüedad tardía al mundo islámico en la Cora de Tudmir: Cultura material y poblamiento paleoandalusi, Alicante, Tesis doctoral inédita.

—, 1993, «La cerámica paleoandalusí del sureste peninsular (Tudmīr): producción y distribución (siglos viI al x)», en: A. Malpica (ed.), La cerámica Altomedieval en el Sur de Al-Andalus, Granada, 37-65.

—, 1996, La cora de Tudmìr de la antigüedad tardía al mundo islámico. Poblamiento y cultura material, Madrid.

Gutiérrez, G., Gamo, B., Amorós, V., 2003, «Los contextos cerámicos altomedievales del Tolmo de Minateda y la cerámica altomedieval en el sudeste de la Península Ibérica», en: L. Caballero, P. Mateos, M. Retuerce (eds.), II Simposio de Arqueología, Mérida. Cerámicas tardorromanas y altomedievales en la Peninsula Ibérica. Ruptura y continuidad, Madrid, Anejos de AEspA XXVIII, 119-168.

Hernández, J.A., Bienes, J.J., 2003, «Cerámicas hispano-visigodas y de tradición en el valle medio del Ebro», en: L. Caballero, P. Mateos, M. Retuerce (eds.), II Simposio de Arqueología, Mérida. Cerámicas tardorromanas y altomedievales en la Peninsula Ibérica. Ruptura y continuidad, Madrid, Anejos de AEspA XXVIII, 307-319.

Jordán, Á.A., Vega, D., Muruzábal, J., Orozco, V., 2016, «Un acercamiento a la vida cotidiana en los primeros años del Islam en el norte de la Península Ibérica: Una cocina del siglo viII d.C. en El Pueyo (Los Bañales, Uncastillo, Z). I. Estudio arqueológico, fragmentos metálicos y óseos», Veleia 33, 137-162.

Larrén Izquierdo, H., 1989, «Materiales cerámicos de La Cabeza: Navasangil (Ávila)», Boletín de Arqueología Medieval 3, 53-74.

Larrén, H., Blanco, J.F.,Villanueva, O., Caballero, J., Domínguez, A., Nuño, J., Sanz, F.J., Marcos, G.J., Martín, M.A., Misiego, J., 2003, «Ensayo de sistematización de la cerámica tardoantigua en la cuenca del Duero», en: L. Caballero, P. Mateos, M. Retuerce (eds.), II Simposio de Arqueología, Mérida. Cerámicas tardorromanas y altomedievales en la Peninsula Ibérica. Ruptura y continuidad, Madrid, Anejos de AEspA XXVIII, 273-306.

López, A., Fierro, J., Enrich, J., Enrich, J., Sales, J., Beltrán de Heredia, J., 2003, «Cerámica tardorromana y altomedieval en el provincia de Barcelona. Siglos vII-X», en: L. Caballero, P. Mateos, M. Retuerce (eds.), II Simposio de Arqueología, Mérida. Cerámicas tardorromanas y altomedievales en la Peninsula Ibérica. Ruptura y continuidad, Madrid, Anejos de AEspA XXVIII, 41-65.

Luezas Pascual, R.A., 1995, «Producciones cerámicas de paredes finas y engobadas del alfar romano de "La Maja" (Calahorra, La Rioja): hornos I y II", Berceo 128, 159-200.

Macías Solé, J.M., 1999, La cerámica comuna tardoantiga a Tárraco. Análisi tipològica i histórica (segles VVII), Tarragona.

OAKLEY, V., JaIN, K., 2002, Essentials in the care and conservation of historical ceramic objects, Londres.

Pascual, J., Ribera I., Lacomba, A., Roselló, M., 2003, "Cerámicas de la ciudad de Valencia entre la época visigoda y omeya (siglos vI, x)", en: L. Caballero, P. Mateos, M. Retuerce (eds.), II Simposio de Arqueología, Mérida. Cerámicas tardorromanas y altomedievales en la Península Ibérica. Ruptura y continuidad, Madrid, Anejos de AEspA XXVIII, 67-117.

Peñil, J., Bohigas, R., Jimeno, R., 1981, «La cerámica en la región cantábrica desde el inicio de la repoblación hasta la aparición del vidriado», Actas del II Coloquio de Cerámica Medieval del Mediterráneo Occidental, Toledo, 227-232.

Rincón Vila, R., 1975, «Cerámicas medievales en Castrojeriz (Burgos)», Sautuola I, 271-285.

Roselló Bordoy, G., 1991, El nombre de las cosas en al-Andalus: una propuesta de terminología cerámica, Palma de Mallorca. 
—, 2011, "Anotaciones sobre la cronología de la cerámica andalusí», en: L. Girón, M. Lazarich, M.C. Lopes (coords.), I Congreso Internacional sobre Estudios Cerámicos, Cádiz, 1335-1367.

Ruiz, A., Bohigas, R., 1989, «Las cerámicas visigodas de poblado en Cantabria y Palencia», Boletín de Arqueología Medieval 3, 31-51.

Solaun Bustinza, J.L., 2005, La cerámica medieval en el País Vasco (siglos VIII-XIII). Sistematización, evolución y distribución de la producción. Vitoria.

Vegas, M., 1973, Cerámica común romana del Mediterráneo occidental, Barcelona.

Vigil-Escalera Guirado, A., 2003, "Cerámicas tardorromanas y altomedievales de Madrid», en: L. Caballero, P. Mateos, M. Retuerce (eds.), II Simposio de Arqueología, Mérida. Cerámicas tardorromanas y altomedievales en la Peninsula Ibérica. Ruptura y continuidad, Madrid, Anejos de AEspA XXVIII, 371-387.

—, 2006, «La cerámica del periodo visigodo en Madrid», en: J. Morín (ed.), La investigación arqueológica de época visigoda en la Comunidad de Madrid, Alcalá de Henares, Zona Arqueológica 6, Vol. III, 704-713.

—, 2007, "Algunas observaciones sobre las cerámicas "de época visigoda" (siglo V-IX d.C.) de la región de Madrid», en: A. Malpica, J.C. Carvajal (eds.), Estudios de cerámica Tardorromana y Altomedieval, Granada, 357-382.

—, 2008, «Evolución tecnotipológica de la cerámica de Gózquez de Arriba (San Martín de la Vega, Madrid) entre los siglos vi y viII A.D. ", en: J.M. Diogo (coord.), Actas das 4. a Jornadas de Cerâmica Medieval e Pós-Medieval. Métodos e resultados para o seu estudo (Tondela, 24-27 outubro de 2000), Porto, 23-26.

Vigil-Escalera Guirado, A., Moreno García, M., Peña Chocarro, L., Morales Muñiz, A., Llorente Rodríguez, L., Sabato, D., Ucchesu, M., 2014, «Productive strategies and consumption patterns in Early Medieval village of Gózquez (Madrid, Spain)», Quaternary International 346, 7-19. 